University of Nebraska - Lincoln

DigitalCommons@University of Nebraska - Lincoln

Nutrition and Health Sciences -- Faculty

Publications

Nutrition and Health Sciences, Department of

$7-2002$

\title{
In-home Prenatal Nutrition Intervention Increased Dietary Iron Intakes and Reduced Low Birthweight in Low-Income African- American Women
}

\author{
Chiquita Briley \\ University of Nebraska-Lincoln \\ Nicole L. Flanagan \\ University of Nebraska-Lincoln \\ Nancy M. Lewis \\ University of Nebraska--Lincoln, nlewis2@unl.edu
}

Follow this and additional works at: https://digitalcommons.unl.edu/nutritionfacpub

Part of the Dietetics and Clinical Nutrition Commons

Briley, Chiquita; Flanagan, Nicole L.; and Lewis, Nancy M., "In-home Prenatal Nutrition Intervention Increased Dietary Iron Intakes and Reduced Low Birthweight in Low-Income African-American Women" (2002). Nutrition and Health Sciences -- Faculty Publications. 18.

https://digitalcommons.unl.edu/nutritionfacpub/18

This Article is brought to you for free and open access by the Nutrition and Health Sciences, Department of at DigitalCommons@University of Nebraska - Lincoln. It has been accepted for inclusion in Nutrition and Health Sciences -- Faculty Publications by an authorized administrator of DigitalCommons@University of Nebraska - Lincoln. 
Published in Journal of the American Dietetic Association 102:7 (July 2002), pp. 984-987; doi: 10.1016/S0002-8223(02)90225-7

Copyright @ 2002 American Dietetic Association. Published by Elsevier Science U.S.A. Used by permission.

Published online March 21, 2003.

\title{
In-home Prenatal Nutrition Intervention Increased Dietary Iron Intakes and Reduced Low Birthweight in Low-Income African-American Women
}

\author{
Chiquita Briley, MS \\ Nicole L. Flanagan MS, RD \\ Nancy M. Lewis PhD, RD, FADA
}

\begin{abstract}
Corresponding author - Nancy M. Lewis, PhD, RD, FADA, Associate Professor, Department of Nutritional Science and Dietetics, 316 E. Ruth Leverton Hall, University of Nebraska-Lincoln, Lincoln, NE 68583-0806; email nlewis2@unl.edu

C. Briley is with Families First Nutrition Education Wellness System, Southern University Cooperative Extension Program, Baton Rouge, LA, USA. N. L. Flanagan is a consultant and N. M. Lewis is an associate professor, both with the department of Nutritional Science and Dietetics, University of Nebraska-Lincoln. At the time of study C. Briley and N. L. Flanagan were graduate research assistants in the department.
\end{abstract}

Low birthweight (LBW), defined as an infant weighing less than 2,500 grams (1), is a major determinant of infant mortality and contributes to infant and childhood morbidity and increased healthcare costs (2-4). LBW occurs due to preterm delivery (length of gestation less than 37 weeks), growth retardation, or both (2). In the United States, higher rates of LBW occur in urban areas with high concentrations of low-income ethnic minorities (5). Results of the 1997 Pediatric Nutrition Surveillance indicate that the rate of LBW in the United
States was $13 \%$ for African-American infants, and $8 \%$ for whites (6). Healthy People 2010 (7) outlines an overarching goal to eliminate health disparities among different segments of the population, including differences that occur by race or ethnicity. 
Reviews of the medical nutrition therapy literature indicate a continuing need to document the specific contribution of the registered dietitian to health outcomes attained (8). In the specific area of prenatal nutrition interventions, Boyd and Windsor (9) concluded there is a need for high-quality prenatal nutrition education programs, including descriptions of program process and content. Published reports of nutrition interventions suggest that programs are more likely to be successful if they are adapted to the particular minority target culture (10) and if they are individualized to the specific client's needs (11). A continuing need exists for well-documented and effective prenatal nutrition interventions designed to reduce the incidence of LBW among minority populations. The objective of this project was to evaluate an in-home prenatal nutrition intervention designed to prevent LBW among lowincome African-American women.

\section{Subjects and Methods}

Volunteers were 27 pregnant African-American women residing in a county with representative rates of LBW similar to those of the United States. The women were recruited through the local county health department WIC Program and they were all at 24 weeks gestation or less. They had no pre-existing health conditions and none of them were following prescribed diets. Women were randomly assigned to either an intervention or a control group.

The intervention protocol (Table 1) was adapted from Widga and LBW is (12) and required a minimum of 6 individualized in-home nutrition assessment and counseling visits. Visits were scheduled weekly for the first 4 weeks, and then monthly for 2 more visits. Some clients delivered their babies within the month following the sixth visit. For those who had not yet delivered, monthly visits continued until parturition. Women in the control group were visited twice. The protocols for the 2 visits were the same as the first and fifth visits of the intervention group, except that teaching and counseling were omitted. Height and weight were measured at the initial visit using a portable stadiometer (Perspective Enterprises, Inc., Kalamazoo,
Mich) and a portable scale (Health0-Meter, Inc., Bridgeview, Ill). Self-reported pre-pregnancy weight was also recorded. Follow-up weights were measured at each visit. Birthweights were obtained from the mothers and were checked with hospital records. The study was approved by the Institutional Review Board for the Protection of Human Subjects in Research Studies.

Table 1. Prenatal nutrition intervention curriculum guide

\begin{tabular}{|c|c|c|}
\hline Visit no. & Topic & Subject matter \\
\hline 1 & $\begin{array}{l}\text { Introduction to intervention and initial } \\
\text { data collection }\end{array}$ & $\begin{array}{l}\text { 24-hour dietary recall } \\
\text { Height and weight measurements } \\
\text { Prenatal questionnaire } \\
\text { Pre-pregnancy questionnaire } \\
\text { Two 24-hour dietary recalls obtained } \\
\text { by telephone following this visit }\end{array}$ \\
\hline 2 & $\begin{array}{l}\text { Basic nutrition weight gain during } \\
\text { pregnancy }\end{array}$ & $\begin{array}{l}\text { Food frequency } \\
\text { Food guide pyramid } \\
\text { Recommended weight gain based on } \\
\text { individual's BMIb } \\
\text { Weight gain graph }{ }^{\mathrm{a}} \\
\text { Hey Baby (Ref. 20) and Baby Under } \\
\text { Construction } \\
\text { Nine-Month Journeyc (Ref. 22) }\end{array}$ \\
\hline 3 & Special nutrient needs during pregnancy & $\begin{array}{l}\text { Discussed calcium. iron, folate, fiber, } \\
\text { and protein sources } \\
\text { Discussion of dietary intake } \\
\quad \text { compared to Food Guide Pyramid } \\
\text { Inside My Mom } \text { (Ref. } 21 \text { ) }^{\text {Discussed goal setting strategies }} \\
\text { Individual goal setting }\end{array}$ \\
\hline 4 & How to make it all work & $\begin{array}{l}\text { Healthy Foods, Healthy Baby } \\
\quad{\text { (teenagers only) }{ }^{c} \text { (Ref. 23) }}^{\text {Menu planning }} \\
\text { Shopping Tips }{ }^{\mathrm{a}} \\
\text { Discussed goal achievement }\end{array}$ \\
\hline 5 & Is it working & $\begin{array}{l}\text { Reassessment of dietary intake } \\
\text { Strategies for managing weight gain }\end{array}$ \\
\hline 6 & Healthy habits as a new mom & $\begin{array}{l}\text { Discussed pre and post pregnancy } \\
\text { computer diet analysis }{ }^{a} \\
\text { Importance of continued good } \\
\text { nutrition } \\
\text { Special needs for breastfeeding }\end{array}$ \\
\hline $7-10$ & Review (optional) & Reinforcement of previous topics \\
\hline
\end{tabular}

a. Copies of teaching materials given to client.

b. BMI=body mass index, defined as weight $(\mathrm{kg}) / \mathrm{ht}\left(\mathrm{m}^{2}\right)$. c. Audiovisual shown at that visit. 
Table 2. Mean daily nutrient intake of low-income African-American women before and after prenatal nutrition intervention

\begin{tabular}{|c|c|c|c|c|c|c|c|c|c|}
\hline \multirow[t]{3}{*}{ Nutrient } & \multirow[t]{3}{*}{$\mathrm{RDA}^{\mathrm{a}}$} & \multicolumn{4}{|c|}{ Intervention group $(n=10)$} & \multicolumn{4}{|c|}{ Control group $(n=10)$} \\
\hline & & \multicolumn{2}{|c|}{ Before } & \multicolumn{2}{|c|}{ After ${ }^{b}$} & \multicolumn{2}{|c|}{ Before } & \multicolumn{2}{|c|}{ After ${ }^{b}$} \\
\hline & & Amount $^{c}$ & $\%$ RDA & Amount $^{c}$ & $\%$ RDA & Amount $^{c}$ & $\%$ RDA & Amount $^{c}$ & $\%$ RDA \\
\hline Energy (kcal) & $2,480^{d}$ & $2,219 \pm 742$ & 89.5 & $2,082 \pm 612$ & 84.0 & $2,458 \pm 72$ & 99.1 & $2,227 \pm 871$ & 89.8 \\
\hline Vitamin B-6 (mg) & 1.9 & $1.6 \pm 0.4$ & 84.2 & $2.3 \pm 0.6$ & 121.1 & $1.7 \pm 0.5$ & 89.5 & $1.7 \pm 0.9$ & 89.5 \\
\hline Calcium (mg) & 1,000 & $984 \pm 385$ & 98.4 & $816 \pm 200$ & 81.6 & $965 \pm 554$ & 96.5 & $739 \pm 424$ & 73.9 \\
\hline Folate $(\mu \mathrm{g})$ & 600 & $271 \pm 69$ & 45.1 & $337 \pm 120$ & 56.2 & $284 \pm 138$ & 47.3 & $245 \pm 155$ & 40.1 \\
\hline Iron (mg) & 30 & $12.6 \pm 3.7$ & 42.3 & $19.4 \pm 8.2^{* *}$ & 64.5 & $15.9 \pm 6.7$ & 53.1 & $14.4 \pm 6.1$ & 48.3 \\
\hline Zinc (mg) & 15 & $10.2 \pm 4.1$ & 67.7 & $10.7 \pm 3.2$ & 71.1 & $11.0 \pm 4.7$ & 73.4 & $10.5 \pm 4.7$ & 70.2 \\
\hline
\end{tabular}

a. RDA=based on 1989 Recommended Dietary Allowance or DRI=based on 2000 Dietary Reference Intakes.

b. After the fifth in-home visit.

c. Intakes presented as means \pm standard deviation.

d. Based on Harris-Benedict formula plus pregnancy and activity factors.

${ }^{\star *} p<.01$

\section{We suggest that programs designed to address the needs of African-American women during pregnancy need to promote culturally acceptable foods to increase dietary intakes of iron, folate, and zinc.}

Dietary data collected from both groups included three 24-hour recalls before and after the intervention. Food models, measuring cups and spoons, and food pictures were used to help clients determine portion sizes. Food Processor Plus computer software (ESHA research, 1995, Salem, Ore) was used to analyze all dietary intakes. Mean daily energy and nutrient intakes were determined before and after the intervention for both groups. Intakes were analyzed and expressed as percent Recommended Dietary Allowance or Dietary Reference Intake $(13,14)$ with $75 \%$ RDA/DRI or more considered within normal limits. SAS statistical software (SAS Institute Inc, Gary, NC, 1994) was used for statistical analysis of all data. Chi-square was used to compare demographic characteristics of the two groups and $t$ tests were used to compare energy and nutrient intakes. Paired $t$ tests were used to identify significant changes in intakes from pre- to post-intervention.

\section{Results and Discussion}

Of the 27 women recruited, 20 completed the study (10 in the intervention group and 10 in the control group). The 7 women who dropped out (5 from the intervention group and 2 from the control group) indicated that time constraints prevented them from scheduling appointments with the nutritionist. Demographic data for those who completed the study indicated that 7 women in each group $(70 \%)$ were 21 years of age or younger, 8 in the intervention group $(80 \%)$ and 10 in the control group $(100 \%)$ were single, 6 in the intervention group $(60 \%)$ and 9 in the control group $(90 \%)$ had a high school education or less, and 8 in the intervention group $(80 \%)$ and 7 in the control group $(70 \%)$ had an annual household incomes of less than $\$ 15,000$. Nine women in the intervention group $(90 \%)$ and 10 in the control group $(100 \%)$ lived with family or friends, and 6 women in each group $(60 \%)$ were unemployed. There were no significant differences between the intervention and control groups in demographic characteristics. Demographic characteristics of women in this study are similar to those reported in larger studies (15).

Mean ( \pm standard deviation) prepregnancy body mass index was within the normal range for both groups (intervention, $24.7 \pm 3.4$; control, 23.2 \pm 4.1 ). Mean weight gain (intervention, $11.9 \pm 6.3 \mathrm{~kg}$; control,
15.2 $\pm 5.1 \mathrm{~kg}$ ) for each group was within the recommended range of 11.4 to $15.9 \mathrm{~kg}$. (16).

Infant birthweight (intervention, $3.54 \pm 0.4 \mathrm{~kg}$; control, $3.06 \pm 0.5 \mathrm{~kg}$ ) was significantly higher in the intervention group than in the control group $(P<.05)$. One birth in the control group was premature and all others births in both groups were full-term births. For the intervention group, iron consumption increased $(P<.01)$ and vitamin B-6 and folate tended to be higher $(P<.10)$ after the intervention (Table 2). Zinc intakes remained at approximately $70 \%$ of the RDA before and after the intervention in both groups. Mean energy intakes before and after the intervention were more than $80 \%$ of the RDA for both groups.

Johnson et al (15) stated that only in regions where there is some form of dietary deprivation could maternal nutrition intervention significantly affect infant birthweight. Results of this study indicate that infants of women in the intervention group (whose nutrient consumption came closer to meeting RDAs/ DRIs than women in the control group) had a higher mean birthweight. Dietary improvements may have increased the chances of bearing an infant of appropriate weight. Anthropometric measurements and number of in-home visits by a nutritionist have been reported as predictive of infant birthweight $(12,15)$. Ed- 
wards et al (17) attributed the reduction in number of LBW infants delivered by participants in their study to the psychological and social support provided by project staff during the participants' pregnancies. In this small study it is not possible to evaluate the independent influence of dietary improvements or nutrition intervention. Furthermore, potential confounding factors were not assessed. Further study is needed to identify the relationship of factors such as diet quality and social support to infant birthweight in at-risk women.

In low-income white women, pre-intervention folate and zinc intakes were above $75 \%$ of the RDA (12). Only iron intake was low $(58 \%$ RDA), but increased to $70 \%$ of the RDA after the intervention. In contrast, in African-American women, folate and zinc intakes were less than $70 \%$ RDA/DRI before the intervention and remained less than $75 \%$ RDA/DRI after the intervention.

One limitation of this study is that we did not obtain data on the interval since the last pregnancy. Rawlings et al (18) reported that short interpregnancy intervals were more frequent among African-American than among white women. Among the African-American women, an interpregnancy interval of less than 9 months was associated with a significantly greater prevalence of preterm delivery and LBW $(P=.02)$. However, among white women, only intervals of less then 3 months between pregnancies were associated with a greater prevalence of prematurity and LBW $(P<.001)$. A second limitation is the small number of women in this study. A follow-up study including a larger, more diverse population (i.e., both urban and rural women) is warranted.

\section{Applications}

Based on the results of this study, we suggest that programs designed to address the needs of African-American women during pregnancy need to promote culturally acceptable foods to increase dietary intakes of iron, folate, and zinc. Due to the high percentage of single mothers and young mothers, a support system including family, friends, and health professionals needs to be incorporated as part of nutrition intervention to facilitate dietary behavior changes and to provide psychosocial support. Practitioners may want to consider how their interventions fit in a broader conceptual framework such as an ecological model that considers the environment around us (19).

Practitioners are encouraged to follow a defined prenatal nutrition intervention protocol and to document their associated outcomes. If we are to make progress in documenting the role of nutrition intervention in reducing the incidence of LBW among minority populations we must use defined protocols. This will make it possible to compare outcomes of prenatal nutrition interventions for lowincome women across different health-care settings. In addition to dietary and birthweight outcomes, nutritionists who have access to biochemical data might include biochemical markers of iron status. Documented outcomes are needed for evaluation of the cost-effectiveness of nutrition care.

Partial funding was provided by the Agricultural Research Division of the University of Nebraska-Lincoln (Journal Series No. 12909).

\section{References}

1. Institute of Medicine; Committee on Nutritional Status During Pregnancy and Lactation. Nutrition During Pregnancy, National Academy Press, Washington, DC.

2. Orr, S.T., James, S.A., Miller, C.A., Barakat, B., Kaikoku, N., Pupkin, M., Engstom, K. and Huggins, G., Psychosocial stressors and low birthweight in an urban population. Am J Prev Med. 12, pp. 459-466.

3. Sable, M.R. and Herman, A.A., The relationship between prenatal health behavior advice and low birth weight. Public Health Rep. 112, pp. 332-339.

4. Lewit EM, Baker LS, Corman H, Shiono PH. The direct cost of low birth weight. Available at: http://0-www.futureofchildren.org.library.unl. edu/LBW/04LBWLEW.htm. Accessed November 1, 2000.

5. Zambrana, R.E., Dunkel-Schetter, C., Collins, N.L. and Scrimshaw, S.C., Mediators of ethnic-associated differences in infant birth weight. J Ur- ban Health: Bull NY Acad Med. 76, pp. 102-116. 6. Centers for Disease Control and Prevention. Pediatric Nutrition Surveillance 1997 full report, US Dept of Health and Human Services, Atlanta, Ga.

7. (Healthy People 2010-Conference Edition, Maternal, Infant and Child Health. Available at: Accessed http://www.health.gov/healthypeople/ Document/HTML/Volume2) 16MICH.htm\#_ Toc471971353.

8. The role of nutrition in maintaining health in the nation's elderly, Institute of Medicine, National Academy Press, Washington, DC.

9. Boyd, N.R. and Windsor, R.A., A meta-evaluation of nutrition education intervention research among pregnant women. Health Educ Q. 20, pp. 327-345.

10. Kumanyika, S.K., Adams-Campbell, L., Van Horn, B., Ten Have, T.R., Treu, J.A., Askov, E., Williams, J., Achterberg, C., Zaghloul, S., Monsegu, D., Bright, M., Stoy, D.B., Malone-Jackson, M., Mooney, D., Deiling, S. and Caulfield, J., Outcomes of a cardiovascular nutrition counseling program in African-Americans with elevated blood pressure or cholesterol level. J Am Diet Assoc. 99, pp. 1380-1388.

11. Higgins, A.C., Moxley, J.E., Pencharz, P.B., Mikolainis, D. and Dubois, S., Impact of the Higgins intervention program on birth weight: A within-mother analysis. J Am Diet Assoc. 89, pp. 1097-1103.

12. Widga, A.C. and Lewis, N.M., Defined, in-home, prenatal nutrition intervention for low-income women. J Am Diet Assoc. 99, pp. 1058-1062. Abstract

13. Food and Nutrition Board Recommended Dietary Allowances. 10th edition, National Academy Press, Washington, DC.

14. National Academy of Sciences. Dietary Reference Intakes: recommended intakes for individuals, National Academy Press, Washington, DC.

15. Johnson, A.A., Knight, E.M., Edwards, C.H., Oyemade, U.J., Cole, O.J., Westney, O.E., Westney, L.S., Laryea, H. and Jones, S., Selected lifestyle practices in urban African-American womenrelationships to pregnancy outcome, dietary intakes and anthropometric measurements. J Nutr. 124 Suppl 6, pp. S963-S972.

16. Institute of Medicine. Committee on Nutritional Status During Pregnancy and Lactation. Preventing Low Birthweight, National Academy Press, Washington, DC.

17. Edwards, C.H., Knight, E.M., Johnson, A.A., Oyemade, U.J., Cole, O.J., Laryea, H., Westney, O.E. and Westney, L.S., Multiple factors as mediators of the reduced incidence of low birth weight in an urban clinic population. J Nutr. 124, pp. S927-S935.

18. Rawlings, J.S., Rawlings, V.B. and Read, J.A., Prevalence of low birth weight and preterm delivery in relation to the interval between pregnancies among white and black women. $N$ Engl J Med. 332, pp. 69-74.

19. Johnson, D.B., Eaton, D.L., Wahl, P.W. and Gleason, $C$., Public health nutrition practice in the United States. J Am Diet Assoc. 101, pp. 529534. Abstract

20. University of Minnesota. Hey baby: How to eat and gain weight to grow the best baby possible. Minneapolis, Minn, 1988.

21. March of Dimes Birth Defects Foundation. Inside my mom (audiovisual). White Plains, NY; 1991.

22. (http://www.milner-fenwich.com/pe/ob.htm Milner-Fenwick. Fetal development: The nine month journey (audiovisual). Milner-Fenwick video productions. Available at:. Accessed May 15, 2001.).

23. Healthy Foods, Healthy Baby (audiovisual), Maternal and Infant Health, Philadelphia Dept of Public Health and Ethnovision, Philadelphia, Pa. 